\section{NOVA TELLVS}

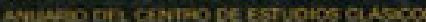

Nova Tellus

ISSN: 0185-3058

novatelu@servidor.unam.mx

Centro de Estudios Clásicos

México

Valdés García, Hilda Julieta

De los baños romanos al temazcalli prehispánico: la interpretación de Vitruvio, V, 10 por Pedro José

Márquez (1741-1820)

Nova Tellus, vol. 26, núm. 2, 2008, pp. 251-270

Centro de Estudios Clásicos

Distrito Federal, México

Disponible en: http://www.redalyc.org/articulo.oa?id=59115497011

- Cómo citar el artículo

Número completo

- Más información del artículo

Página de la revista en redalyc.org

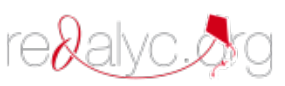

Sistema de Información Científica

Red de Revistas Científicas de América Latina, el Caribe, España y Portugal Proyecto académico sin fines de lucro, desarrollado bajo la iniciativa de acceso abierto 


\title{
De los baños romanos al temazcalli prehispánico: la interpretación de Vitruvio, V, 10 por Pedro José Márquez (1741-1820)
}

\author{
Hilda Julieta VALDÉS GARCÍA \\ Universidad Nacional Autónoma de México \\ helade01@hotmail.com
}

\begin{abstract}
RESUMEN: Tras la orden de expulsión de los jesuitas dictada por Carlos III en 1767, el jesuita mexicano Pedro José Márquez marchó al destierro. Establecido en Roma, se dedicó por completo a estudiar la arquitectura antigua y a reivindicar la obra de Vitruvio. Interesado en la incipiente ciencia arqueológica, participó en diversas excavaciones y logró publicar sus investigaciones. El presente estudio analiza los capítulos XLII a XLVI de su obra Delle case di città degli antichi Romani, secondo la dottrina di Vitruvio (Roma, 1795), donde, a partir de De architectura, V, 10, Márquez compara la estructura del laconicum romano con el temazcalli (o "casa de baños") prehispánico.
\end{abstract}

$$
* * *
$$

ABSTRACT: As a result of the decree of expulsion issued in 1767 by King Charles III of Spain against the Jesuits, the Mexican Jesuit Pedro José Márquez went into exile. Once settled in Rome, he got engaged in a thorough study of ancient architecture, whereby he undertook to vindicate Vitruvius's work. He was very interested in the new archaeological explorations and took part in several excavation campaigns, being able to publish his own researches. This article deals with chapters XLII to XLVI from his work Delle case di città degli antichi Romani, secondo la dottrina di Vitruvio (Rome, 1795), where Márquez (based on De architectura, V, 10) compares the structure of the Roman laconicum with the pre-Hispanic temazcalli or "house of heat".

PALABRAS ClAVE: arquitectura, baño romano, Pedro José Márquez, temazcalli, Vitruvio.

RECEPCIÓN: 30 de septiembre de 2008.

ACEPTACIÓN: 3 de noviembre de 2008. 


\title{
De los baños romanos al temazcalli prehispánico: la interpretación de Vitruvio, V, 10 por Pedro José Márquez (1741-1820)
}

\author{
Hilda Julieta VALDÉs GARCíA
}

Los jesuitas marcharon al destierro en 1767 tras la Pragmática Sanción ${ }^{1}$ dada por Carlos III, a través de la cual se dictaba la expulsión de estos religiosos de los dominios de la corona de España y se decretaba la incautación del patrimonio que la Compañía de Jesús tenía en esos reinos.

La corona española imputó a la Compañía, entre otras cosas, el poder que estaba acumulando, la transformación ideológica de sus miembros, el crecimiento de sus centros educativos en las metrópolis y provincias, así como el apoyo que prestaba al Papa en sus enfrentamientos con los gobiernos de las naciones europeas.

Ciertamente el problema no era nuevo, la creación de la leyenda antijesuítica por parte de sus detractores de siglos pasados se avivó; ${ }^{2}$ Carlos III no fue el primero en tomar esta medida para salvaguardar los intereses del reino; ya en 1759 el rey José I había decretado la expulsión de los jesuitas de Portugal, sin considerar la oposición papal y, pocos años después, en 1764, también serían expulsados de Francia.

Cuando la Pragmática Sanción fue ejecutada en la Nueva España, Pedro José Márquez Durán, oriundo de San Francis-

\footnotetext{
1 "Pragmática sanción de su Magestad en fuerza de ley para el estrañamiento de estos Reynos a los Regulares de la Compañía, ocupación de sus temporalidades, y prohibición de su restablecimiento en tiempo alguno, con las demás prevenciones que expresa. El Pardo, 2 de abril de 1767”.

${ }^{2}$ Wright, 2005, pp. 149-181.
} 
co del Rincón, ${ }^{3}$ Guanajuato, era estudiante de Teología en el Colegio de San Pedro y San Pablo de México. En el puerto de Veracruz, marchó al destierro junto con sus hermanos de orden, entre los que se encontraban Francisco Javier Alegre, José Rafael Campoy, Francisco Javier Clavijero, Juan Luis Maneiro y Andrés Cavo, entre otros. "Terminó sus estudios en Bolonia y se ordenó sacerdote el $1^{\circ}$ de noviembre de 1769 ". 4 Posteriormente se estableció en Roma, allí publicó su primera obra Tavole nelle quale si mostra il punto del mezzo giorno e della mezza notte, del nascere e tramontare del sole, secondo il meridiano di Roma, Roma, Presso il Salomoni, 1790.

No sabemos en qué momento sus estudios se apartaron de la ciencia astronómica; el mismo Márquez nos relata en las páginas introductorias de su libro sobre las casas de los antiguos romanos que su interés por la obra de Vitruvio ${ }^{5}$ había surgido tras haber escuchado a dos eruditos discutir sobre arquitectura; pues, mientras el primero desacreditaba la obra del arquitecto romano, el segundo valoraba la trascendencia de éste y la vigencia del De architectura; como este último lograra con su argumentación una verdadera apología de Vitruvio, el jesuita mexicano determinó profundizar sobre este arte, de aquí nació su "pasión" por el De architectura, al que dedicaría su vida entera, en una búsqueda por reivindicar la imagen del arquitecto romano.

Se sabe que los estudiosos del siglo XVIII comenzaron a apartarse del De architectura de Vitruvio por "los muchos errores" con que había sido transmitido. La novedosa labor anticuaria del siglo de las luces permitió a los estudiosos cotejar las fuentes escritas con los datos materiales; la fruición con que se llevaban a cabo las expediciones arqueológicas dieron

\footnotetext{
${ }^{3}$ Los datos biográficos han sido tomados principalmente de Orozco, 1941, Sosa, 1985, y Valdés, 2007.

${ }^{4}$ Decorme, "Pedro José Márquez", fol. 1.

${ }^{5}$ Delle case, p. XXXV.
} 
paso a la proliferación no sólo de nuevos tratados escritos en lenguas vernáculas, aunque basados en Vitruvio, sino también a los escritos sobre arte grecolatino que contribuyeron al desplazamiento del escritor romano, ya que se pensaba que los tratadistas contemporáneos habían superado el escabroso texto del autor latino y subsanado la información que éste había omitido o expuesto con brevedad.

Gracias al contacto con los becarios españoles en Roma, el padre Márquez se vio favorecido con el mecenazgo del embajador de España en Italia, Don José Nicolás de Azara (17301804), quien reconoció a nuestro compatriota su erudición. En efecto, bajo este mecenas, el guanajuatense escribió sus más importantes obras referentes a Vitruvio y al mundo clásico.

Entre los pensionados españoles en Roma se encontraba Silvestre Pérez, uno de los más importantes arquitectos neoclásicos y con quien nuestro autor, interesado en la incipiente ciencia arqueológica, emprendió excavaciones y viajes a los alrededores de Ostia, ${ }^{6}$ indagando las conexiones posibles entre las descripciones de Plinio el joven y de Vitruvio con la realidad de las ruinas en torno al importante tema de las villas romanas. Como producto de estas investigaciones de campo Márquez publicó las siguientes obras:

Delle case di città degli antichi Romani, secondo la dottrina di Vitruvio Esposta da D. Pietro Márquez, Messicano, Roma, Presso il Salomoni, 1795.

Delle ville di Plinio il giovane, con un appendice sugli atri della S. Scrittura, e gli scamilli impari di Vitruvio, Roma, Presso il Salomoni, 1796.

Dell'ordine dórico ricerche dedicate alla Reale Academia di S. Luigi di Zaragoza..., Roma, Presso il Salomoni, 1803.

Esercitazioni architettoniche sopra gli spettacoli degli antichi, con appendice sul bello in generale, Roma, Presso il Salomoni, 1808.

\footnotetext{
${ }^{6}$ Bérchez, 1981, p. XLIV.
} 
Illustrazioni della villa di Mecenate in Tivoli, Roma, Presso il Salomoni, 1812.

Sobre esta misma temática de arquitectura y arqueología antigua romana dejó obras manuscritas que durante mucho tiempo se tuvieron por perdidas:

\section{Villa di Mecenate (Disertación). ${ }^{7}$}

Apuntamientos por orden alfabético pertenecientes a la arquitectura, donde se exponen varias doctrinas de M. Vitruvio Polion, obra compilada por Pedro Joseph Márquez, Socio Honorario de las Academias de Bellas Artes de Roma, de Madrid, de Florencia, de Bolonia y de la Archeologica Romana. Se coordinó en Roma del 1784 al $1806 .{ }^{8}$

A éstas habría que añadir la referente a la arquitectura prehispánica, sobre los monumentos arqueológicos de Tajín y Xochicalco: Due Antichi Monumenti di Architettura Messicana. Illustrati da D. Pietro Marquez, ${ }^{9}$ Socio della Acad. di Belle Arti di Madrid, di Firenze e di Bologna, dedicati alla Molto Nobile, Illustre ed Imperiale Città di Messico, Roma, 1804.

\footnotetext{
${ }^{7}$ Manuscrito hológrafo, lo hallé en el Archivo Histórico de la Provincia Mexicana de la Compañía de Jesús. Gutiérrez, 1994, p. 85, sugiere que el manuscrito intitulado: Comentari sopra la vita di Mecenate, resguardado en el Fondo Jesuítico de la Biblioteca Nacional "Vittorio Emmanuele", Roma, núm. 113 (2242), podría ser obra de nuestro autor. Ignoro si se trata del mismo documento.

${ }^{8}$ Consta de aproximadamente 1300 fojas. He podido localizar el original y dos copias. El original se encuentra en dos volúmenes en la Biblioteca Cervantina del ITESM, Colección Robredo, ms. 108 (hológrafo). El duplicado en el Archivo Histórico de la Provincia Mexicana de la Compañía de Jesús, sección VIII, Colocación Márquez. La copia hológrafa definitiva, quizá para la imprenta, se encuentra resguardada en la Biblioteca Nacional de Madrid, mss/ 2456, 2457, 2458 y 2459. Gutiérrez, 1994, afirma que hubo la intención de publicar en México esta obra en 1856, pocos años después de ser restablecida la Academia de San Carlos. Un tomo adicional denominado Tablas que contiene las ilustraciones (impresas y dibujadas) alusivas a algunas entradas del diccionario se encuentra en el Archivo Histórico de la Provincia Mexicana de la Compañía de Jesús; el repositorio español carece de éste.

${ }^{9}$ Parte de esta obra fue traducida por Francisco del Paso y Troncoso y publicada en 1882-1886 en los Anales del Museo Nacional de México.
} 
Sus publicaciones llamaron poderosamente la atención por su talento, por la elegancia de su estilo, por el dominio de la lengua latina y por la solidez de su ciencia. A guisa de ejemplo, Silvestre Pérez, en calidad de Académico de mérito de la Real Academia de Bellas Artes de San Fernando de Madrid, examinó y aprobó la obra de Márquez Delle case di città degli romani; en el breve texto de su aprobación, destacó la erudición y buen juicio del autor, la "savia interpretazione dei difficili ed oscuri luoghi vitruviani”, considerándola útil y digna de publicarse. Más aún, cuando regresó a España en 1796, "divulgó esta obra en los medios académicos españoles, concretamente en la Academia de San Carlos de Valencia". ${ }^{10}$

Esta obra, dedicada a la Real Academia de Bellas Artes de San Fernando, que recibió a nuestro autor como Académico de honor en el año de $1797,{ }^{11}$ fue la primera publicación del P. Márquez sobre arqueología romana; consta de 47 capítulos a los que preceden la dedicatoria, un prefacio apologético y 6 láminas que apoyan su exposición. El autor señala que el texto latino utilizado es el de Bernardo Galiani (Nápoles, 1758); entre otras fuentes, cita los trabajos de Guillaume Philandrier (en su edición de 1552), Andrea Palladio (1570), Giovanni Poleni (1739) y José Ortiz y Sanz (1787); que los monumentos a los que hace mención son los de Roma y que para las medidas de éstos sigue a Antoine Desgodetz (1682). ${ }^{12}$

Delle case di città es, en su conjunto, un estudio hermenéutico de algunos capítulos de los libros V y VI del De architectura. Del capítulo I al XXXII trata de los espacios domés-

\footnotetext{
${ }^{10}$ Bérchez, 1981, p. XLIV.

${ }^{11}$ Fernández Agudo, p. 447. http://www.cervantesvirtual.com/servlet/SirveObras/ 01715307326704082900035/ima0076.htm

${ }^{12}$ Antoine Desgodetz (1653-1728), arquitecto y arqueólogo francés, con su obra Les edifices antiques de Rome dessinés et mesurés trés exactement (Paris, 1682) intentó determinar las proporciones precisas de muchas construcciones romanas como el pórtico del Panteón o el Templo de Vesta en Tívoli, su obra fue reeditada en 1729 y en 1779 , la cual fue de mucha ayuda para los arquitectos clasicistas y neoclásicos.
} 
ticos, del XXXIII al XLVI de la basílica y de los baños. En el último capítulo XLVII Disegno di una casa romana explica las diversas secciones que componían una vivienda romana. (Cf. Figura 1, números 1-10 parte superior izquierda.) Cabe señalar que la planta que se ilustra corresponde más a una edificación de carácter palaciego que a la reconstrucción de una casa romana. Al respecto, García Melero alude que el acierto de Márquez "se halla en percibir la aplicación y proyección modernas de las teorías vitruvianas". ${ }^{13}$

En su desarrollo, Márquez analiza la distribución de los aposentos; en la primera parte trata del vestíbulo, de los distintos tipos de cavedii o patios de la casa, del atrio, del tablinio, del peristilo, de las columnas, etcétera; dedica varios capítulos a los diversos estilos de puertas y puntualiza la descripción de las bibliotecas y pinacotecas. ${ }^{14}$ Quizá los temas tratados con mayor extensión y precisión son los correspondientes a las basílicas y a los baños, justamente por la brevedad con que los abordó el escritor romano.

Los capítulos XLII a XLVI están dedicados totalmente a los baños romanos. ${ }^{15}$ Siguiendo el orden del De architectura, V, 10, Márquez se propuso examinar "las doctrinas allí contenidas": ${ }^{16}$ el lugar donde deben erigirse los baños; la orientación de las estancias cálidas y templadas; sobre los contenedores de agua caliente, tibia y fría; del hipocausto $;{ }^{17}$ sobre la construcción de las estancias cálidas; de las otras estancias para bañarse

\footnotetext{
${ }^{13}$ García, 2002, p. 209.

${ }^{14}$ Delle case, pp. 215-224.

${ }^{15}$ XLII Si tratta dei bagni (De la elección del lugar donde construir los baños); XLIII Dei tre vasi per l'acqua, e dell'ipocausto; XLIV Delle stanze calde; XLV Mobili da bagnarsi nelle stanze calde; XLVI Del Laconico.

${ }^{16}$ Ibidem, p. 325.

${ }^{17}$ Este vocablo será explicado más adelante por Márquez, al parecer desde su época el significado que se le asignaba era tanto del instrumento donde se generaba el calor, como la habitación misma. Véase la definición del DRAE de hipocausto:

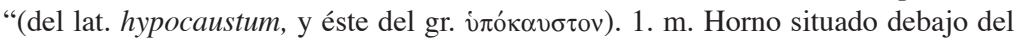
pavimento, que en la antigüedad clásica caldeaba las habitaciones. 2. m. Habitación caldeada por este horno".
} 
y de los muebles necesarios en éstas y, finalmente, del laconicum o lugar para sudar.

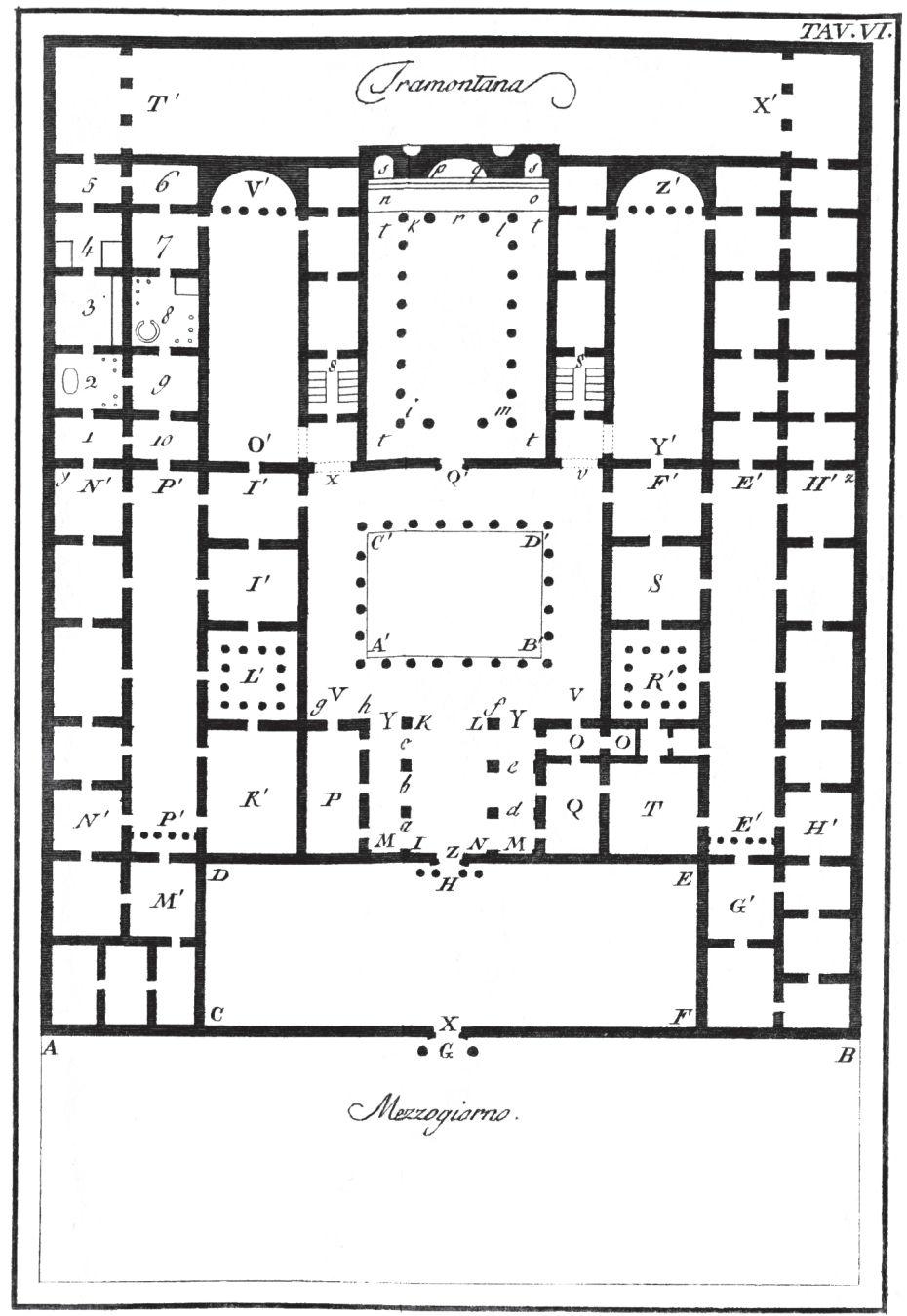

FIG. 1. Tav. VI Disegno di una casa romana

De la sucinta exposición del arquitecto romano, Pedro Márquez lleva a cabo un estudio completo sobre la estructura, 
disposición y vigencia de los preceptos de Vitruvio. El afán de nuestro autor en aclarar los términos del lenguaje vitruviano lo llevaron a definir cada uno de los términos que componen los baños romanos. Por ejemplo, los vocablos hipocaustum e hipocausis, son definidos en su diccionario o Apuntamientos por orden alfabético pertenecientes a la arquitectura, donde se exponen varias doctrinas de M. Vitruvio Polión de la siguiente manera:

Hipocausto: Hypocaustum: así llama Vitr. 5, 10. al fogón sobre el cual se ponían los tres vasos o calderos para el agua caliente, templada y fría, que eran necesarios en los baños antiguos. El nombre Hypocausis que parece dar al mismo fogón, yo diría, que de sus expresiones, se saca significar este sitio propio del fuego, y aquel al entero fogón, que comprehende no sólo el fuego, sino también la obra sobre que se asientan los vasos. ${ }^{18}$

Sistemáticamente Márquez precisa el funcionamiento de cada una de las partes que conforman los balnea que, en un principio de carácter privado y rústico, pasaron a ser públicos, o bien, privados en casas de acaudalados romanos. ${ }^{19}$

Como apoyo para su presentación, el autor hace referencia a vestigios arqueológicos y monumentos contemporáneos donde puede constatarse lo escrito en el De architectura:

Per comprovare noi le materie, e per fare più intelligibili gli oggetti, di che tratta Vitruvio, abbiamo quasi sempre proposto quelli esemplari, che potessero rassomigliarneli, se non del tutto, in gran parte: così abbiamo spiegato i labri colle tazze antiche di marmo; gli alvei coi nostri bagni moderni; le scuole coi sedili della stanza di Pozzuolo; e così adesso vogliamo paragonare i laconici, e luoghi dove si entrava a sudare con certi luoghi quasi del tutto simili ai laconici dei Greci e Romani, dove gli indigeni

\footnotetext{
18 Apuntamientos, p. 993. (El hológrafo carece de numeración, la que asigno corresponde a la foliación de la impresión del microfilm.)

${ }^{19}$ Cf. Malissard, 1994, pp. 73-120.
} 
Messicani sino al di d'oggi usano bagnarsi col solo sudare dentro di essi. Chiamano i Messicani questi luoghi nell'antico loro linguaggio Temazcalli, che vuol dire, casa o luogo da bagnarse al caldo; chi è prattico di questo linguaggio sà, quanto felicemente si spiegano colle loro composte parole le proprietà specifiche degli oggetti...20

A continuación, describe ampliamente la estructura y funcionamiento del baño americano:

Consiste il Temazcalli, ossia laconico messicano in una fabbricetta emisferica, che sopra pianta circolare si alza immediatamente da terra; ha la sua entrata da una parte, capace solo di entrarvi un uomo quanto può inclinato; dalla parte opposta ne ha una o più pietre di quelle che resistono al fuoco; una facciata di esse pietre resta dentro il temazcalli, ed altra al di fuori; l'uso di queste pietre è il comunicare dentro il luogo il calore, che in virtù del fuoco esterno concepiscono; perchè al di fuori ivi appunto dove sono le dette pietre si accende un sufficiente fuoso atto a riscaldare esse pietre quanto è di bisogno. Questo è il modo più artifizioso di riscaldare il temazcalli, perchè ancora si riscalda, mettendo a dirittura dentro di esso il fuoco; oppure mettendo pietre altronde già infocate per l'uso che si dirà. ${ }^{21}$

Para complementar el tema, Márquez da noticia de que la diversidad de los temazcalme estaba relacionada con los estamentos sociales de los usuarios; así, encontramos que los había colectivos y particulares:

I poveri fanno il loro temazcalli isolato, ed in vicinanza alla abitazione per passarvi immediatamente usciti dal bagno, a lavarsi, asciugarsi, riposare, etc... Ma le persone commode gli usano dentro una stanza a questo fine destinata: ed in tal maniera, che pare avere questi voluto eseguire quanto Vitruvio dice delle stanza poco fa spiegate, dove nelle palestre greche si metteva da una

\footnotetext{
${ }^{20}$ Delle case..., pp. 361-362.

${ }^{21}$ Ibidem, p. 362.
} 
parte il laconico, e dall'altra il bago caldo; perchè effettivamente nelle dette stanze messicane si vede da una parte il temazcalli attaccato al muro, e giusto attaccato per dove sono le pietre da poter essere riscaldate col fuoco acceso fuori della stanza, vi sono dei catini o bagnarole con dell'acqua calda, o tiepida da lavarsi quegli che escono dal temazcalli. Così sono i luoghi venali, dove pagando il pattuito, vanno molti a bagnarsi nel temazcalli. ${ }^{22}$

Las particularidades de cómo se tomaba el baño también son mencionadas detalladamente:

Il bagno poi dentro a questo si eseguisce così: introdottevi quelle tante persone che si hanno da bagnare, e che ammette la capacità del luogo; (perchè vi sono dei piccoli, e dei grandi da starvi sino a cinque o sei,) uno di essi con qualche ramo o foglie di erba o anche colla mano spruzza dell'acqua contro le riscaldate pietre; indi si alzano in quantità dei vapori caldi, che fanno successivamente sudare in gran copia quanti stanno dentro: dopo che hanno sudato quanto hanno di bisogno, escono a lavarsi colla calda, o tiepida acqua dei catini, e poi passano ad asciugarsi, a riposare, etc.

Las diferencias entre ambos baños expuestas por Márquez son las siguientes:

Benchè la volta del temazcalli o laconico messicano si alzi da terra immediatamente, e non sopra un muro tondo come il laconico dei Romani; e benchè non abbia in mezzo quel buco per temperare il calore, che dice Vitruvio aveva il laconico antico; non perciò è meno acconcio a conseguire il preciso fine di sudare, nè lascia di farci concepire, come questo effeto si poteva ottenere coll'uso del laconico antico, anzi supplisce quella istruzione, che Vitruvio non si curò di dare, perchè parlava con quei che erano consapevoli. ${ }^{23}$

Tras la disertación sobre los dos tipos de baños de vapor, el europeo y el americano, Márquez concluye con la sugerencia de un posible origen común de éstos, cuestión que:

\footnotetext{
22 Ibidem, p. 363.

${ }^{23}$ Ibidem, p. 364.
} 
E chi sà, se i primi ascendenti dei Messicani portarono dal mondo antico la usanza di questi bagni vaporosi, quale i loro attuali discendenti conservano ancora, come era nella sua primitiva origine; mentre i Greci, ed i Romani avendola forse appresso dalla stessa fonte, che i Messicani, prima la immutarono, e poi l'abbandonarono affatto? Che se è così, giacchè da questi non possiamo presentemente imparare, come era il laconico, che maravaglia, che quegli dell'altro mondo cel possano insegnare? Qualche altra nazione dell'Asia, secondo gli scrittori di viaggi, usano i bagni vaporosi come i Messicani, ma di essi non sono io a portata di farne la descrizione, come dei temazcalli; di questi ne ho veduto alcuni, essendo nato, e vissuto in quei Regni per più anni: e giusto per averli veduti, e per essere informato dei loro usi, ho creduto, riflettendo sopra Vitruvio, poterli paragonare coi laconici, per spiegare questi con quelli. ${ }^{24}$

Llama nuestra atención que el autor mencione sólo los temazcalme sin respiradero en la cámara principal; su compatriota y hermano de orden Francisco Javier Clavijero, en la Historia antigua de México, menciona esta variante de la construcción como "estructura común del temazcalli" y remite al lector a la ilustración (Fig. 2), aunque también añade que "en algunas partes se reduce a un pequeño edificio o choza cuadrilonga y sin bóveda ni hornilla, pero más abrigada". ${ }^{25}$

Es seguro que Márquez tenía conocimiento de que el temazcal no necesariamente era abovedado, desde la época prehispánica los había de las más diversas formas: rectangulares, cuadrados, como se muestra en la Fig. 3; se construían subterráneos, semisubterráneos o al nivel del suelo. ${ }^{26}$

\footnotetext{
${ }^{24}$ Ibidem.

${ }^{25}$ El P. Clavijero dedicó un apartado al temazcal, describe e ilustra la construcción, menciona sus usos, entre los que destaca el terapéutico o medicinal, pp. 388389, que predomina hasta nuestros días. Cf. Mendoza, 2004, y Lillo, 2007.

${ }^{26}$ Mendoza, 2004, p. 161, señala que en la actualidad "esta variabilidad de diseños y materiales de construcción de los temazcalme hace difícil una descripción general, por lo que cada una de sus partes tiene que ser analizada para obtener una idea general de su diversidad, aunque la forma y tamaño no cambian su utilidad práctica ritual”.
} 
264 VALDÉS GARCÍA / DE LOS BAÑOS ROMANOS AL TEMAZCALLI PREHISPÁNICO

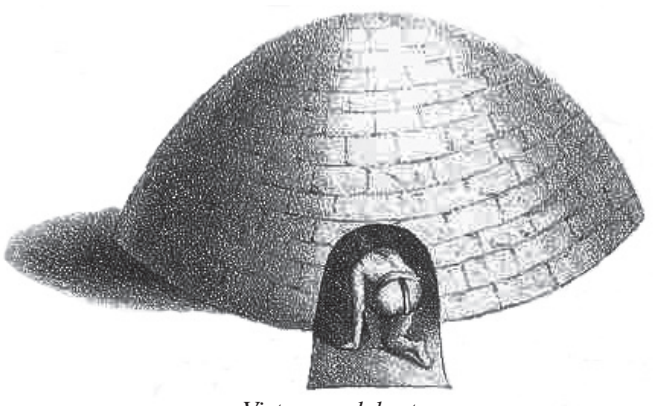

Visto por delante

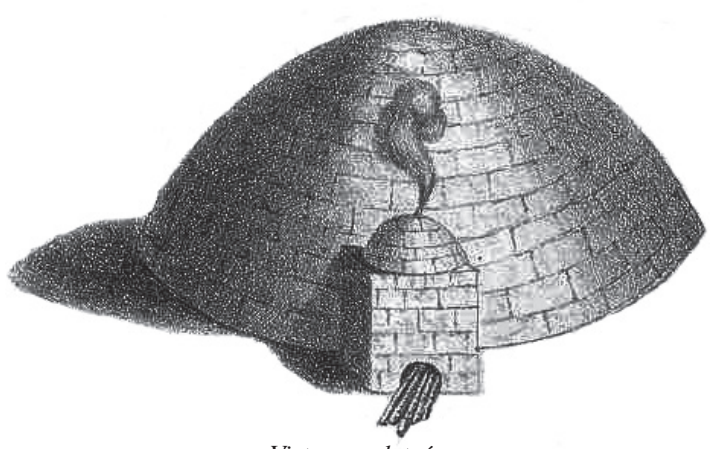

Visto por detrás

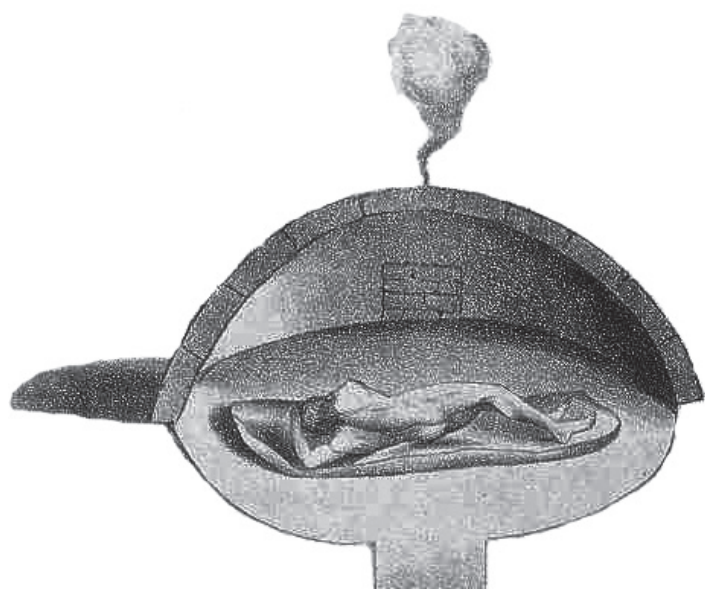

FIG. 2. "Temazcalli o hipocausto mexicano"27

${ }^{27}$ Tomada de Lozoya, p. 54. 


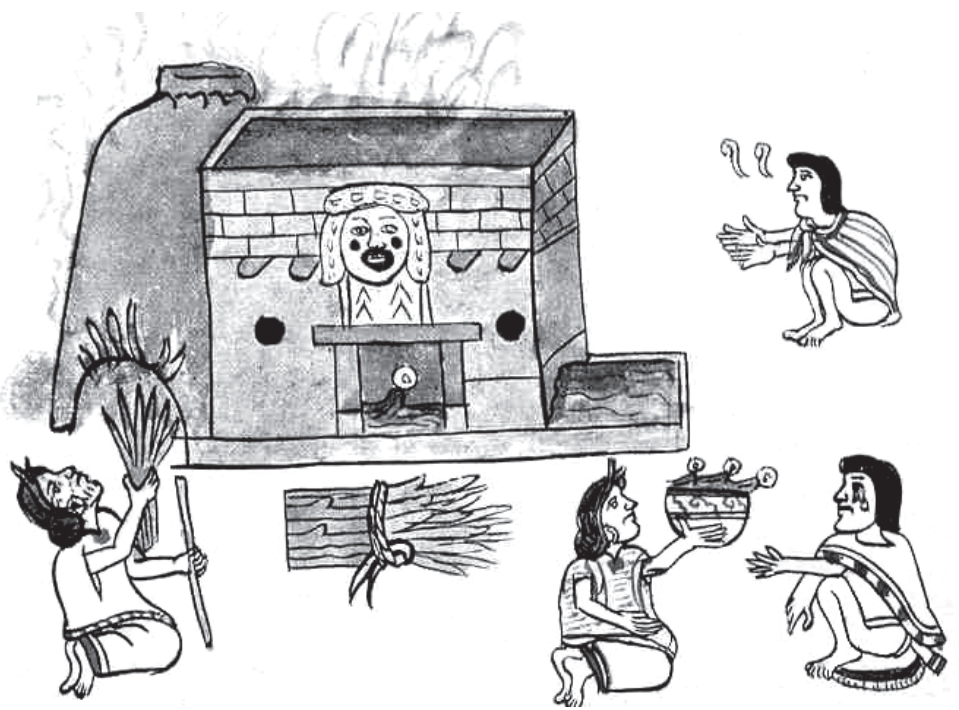

FIG. 3. Representación de un temazcal en el Códice Magliabechiano, f. 77r ${ }^{28}$

¿Cómo ha de interpretarse entonces el interés en asimilar el término laconicum al de temazcal? Es evidente, pues, que el autor desea señalar enfáticamente el uso de la bóveda en el Nuevo Mundo, para manifestar que los antiguos arquitectos americanos dominaron el uso de esta construcción.

La comparación entre estas dos construcciones de baños fue expuesta por Márquez en otros lugares: ${ }^{29}$ en Due antichi monumenti, al hacer la descripción del salón "D” subterráneo del monumento de Xochicalco, refiere:

La estancia o salón $D$ merece observaciones más particulares. $\mathrm{Su}$ techumbre no era sino una verdadera bóveda trabajada en la

\footnotetext{
28 Tomada de Lozoya, 2005, p. 54. Otros códices que contienen representaciones pictóricas del temazcal son: Tudela, Vaticano B, Borgia y Aubin. Cf. Ortiz Buitrón, 2005, pp. 52-53.

${ }^{29} \mathrm{Su}$ primer acercamiento a los términos vitruvianos fue registrado en los Apuntamientos que el jesuita emprendió, los cuales, dice: "me han servido en gran parte para compilar las obras, que separadamente he dado a luz, por lo que no deberá hacer fuerza el ver tratados algunos puntos casi del mismo modo en una y otra parte", p. 6.
} 
roca viva; los dos pilares $b b$ vinieron a ser como en virtud del ingenio, con el cual, mientras se forma la estancia excavando y rompiendo la roca, según el diseño, iban dejando, con industria, aquella porción de macizo que requería su forma. ¿No son éstas en esencia dos columnas destinadas a soportar el techo, o la bóveda de la estancia? Ellos, los mexicanos, nos consta que habían fabricado bóvedas semejantes a las nuestras; pero a buen seguro, conocieron la especie, porque las hicieron tanto en este salón como en todos los corredores que conducen al mismo, como hasta ahora las hacen aunque pequeñas y a menudo con ladrillos crudos, para cubrir las estufas llamadas en su lengua temazcalli, o sea, estancias para bañarse con calor. De estos temazcalli hemos hablado en otra ocasión por la semejanza que tienen con los antiguos laconici de Grecia y de Roma. ${ }^{30}$

Así, en los Apuntamientos exalta las fábricas arquitectónicas mesoamericanas y el dominio que los constructores tenían de los materiales: "De las ruinas el Palacio de los Reyes de Texcoco se saca fácilmente que usaban bóvedas, y los lacónicos que usan hasta ahora y llaman Temazcalli, aunque obras chicas, son de bóveda". ${ }^{31}$

Más adelante, señala:

Vimos en otra parte cómo los mexicanos y los peruanos antiguos no solamente inventaron por sí solos lo más fácil y necesario de la fabricación, sino que también edificaron obras de arte, que sin dificultad podían comparecer entre las del mundo antiguo. La comparación que hacían los primeros conquistadores de una con otra en sus relaciones y escritos, es muy ordinaria y los astrónomos filósofos, que en este siglo registraron algunos residuos hacen de ellos elogio, semejantes de los que harían de las ruinas de la África o de la Asia. Prueba de lo que en realidad había en aquellos países es a saber: materiales en abundancia, regiones oportunas, situaciones ventajosas, riquezas de todo género y sobre todo artífices prácticos en el manejo de las materias y cono-

\footnotetext{
${ }^{30}$ Due antichi..., p. 23; Fernández, 1972, p. 152.

${ }^{31}$ Apuntamientos, p. 910.
} 


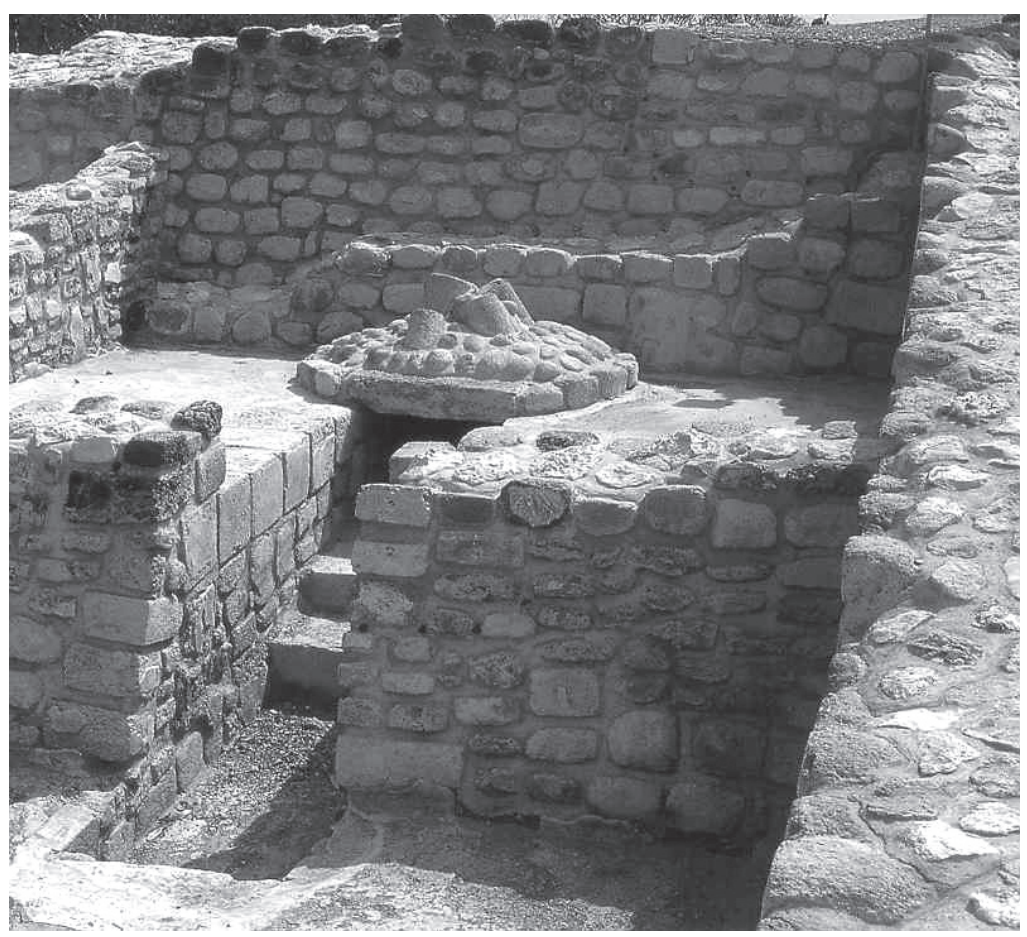

FIG. 4. Baño de vapor. Acrópolis de Xochicalco ${ }^{32}$

cedores de sus cualidades, con que hacían de ellas artificialmente el uso más conveniente que se puede añadir, para hacernos cargo de lo que hicieron después por una parte la natural docilidad de los habitadores y, por otra, el gusto que tenían de poner por obra las invenciones que se les proponían como nuevas. ${ }^{33}$

Es verdad que nuestros jesuitas expulsos manifestaron en el exilio su amor e interés por la patria con un "acendrado mexicanismo", como lo llamó Méndez Plancarte; su alta estima por las culturas indígenas, "su actitud hondamente comprensiva para todas las expresiones de la vida prehispánica, aun las más lejanas y contrarias a nuestra sensibilidad cristiana

\footnotetext{
32 Tomada de López, 2001, p. 85.

${ }^{33}$ Apuntamientos, p. 968.
} 
y occidental estuvo siempre presente en sus escritos". ${ }^{34}$ Las palabras que el propio Márquez escribió en una nota marginal al concluir sus Apuntamientos confirman lo anterior:

Si nos hemos detenido un poco en este último punto de la Arquitectura en América, el prudente lector sabrá disculparlo a quien las distancias, bien que grandes, así de lugar como de tiempo no han sido suficientes a hacerlo olvidar de su amada patria. ${ }^{35}$

Estimo que el interés de Márquez va más allá de una simple exaltación de las culturas prehispánicas en el destierro, me inclino a pensar que en toda la producción de este erudito jesuita hubo una firme determinación por establecer la universalidad de la arquitectura, partiendo de la clásica grecolatina, ciertamente, pero con la visión de reconocer en cada civilización su estética propia. Por ello, considero que su obra y su persona deben ser reivindicadas, a partir de una nueva lectura de sus obras impresas y del rescate de las que quedaron manuscritas.

Pedro José Márquez puede ser reconocido como el primer teórico de la estética mesoamericana, ${ }^{36}$ como uno de los expositores del academicismo y neoclasicismo español ${ }^{37} \mathrm{y}$, muy probablemente, el único mexicano que participó activamente en las expediciones arqueológicas europeas del siglo XVIII.

\footnotetext{
${ }^{34}$ Méndez Plancarte, 1979, p. 21.

${ }^{35}$ Nota marginal escrita en la última hoja del Suplemento 4 de los Apuntamientos, "Historia de la Arquitectura", bajo la entrada Arquitectura en América, p. 983.

${ }^{36}$ Valdés, 2000, pp. 60-65.

${ }^{37}$ Cf. Bérchez, 1981, LXXII-LXXIX; García, 2002, pp. 208-210.
} 


\section{BIBLIOGRAFÍA}

Bérchez Gómez, Joaquín, "La difusión de Vitruvio en el marco del Neoclasicismo español", introd. a la ed. facs. de Joseph Castañeda de C. Perrault (trad.), Compendio de los diez libros de arquitectura de Vitruvio, Murcia, Colegio de Aparejadores y Arquitectos Técnicos, 1981.

CERVERA Vera, Luis, El códice de Vitruvio hasta sus primeras ediciones impresas, Madrid, Instituto de España, 1978.

ClaviJero, Francisco Javier, Historia antigua de México, t. II, México, Porrúa, 1958.

DeCorme, Gerardo, Varones ilustres de la provincia de México muertos en el siglo diez y nueve. Compilación histórica de varios autores (texto mecanografiado, Biblioteca Dr. Eusebio Dávalos Hurtado del MNAH-INAH, Fondo jesuita, carpeta XXV, doc. 4/19: "Pedro José Márquez").

Fernández, Justino, Pedro José Márquez (1741-1820). Sobre lo bello en general y Dos monumentos de arquitectura mexicana Tajín y Xochicalco, México, UNAM, 1972.

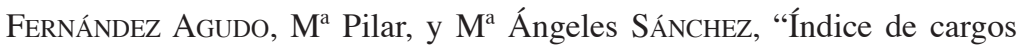
académicos de la Real Académica de Bellas Artes de San Fernando en el siglo XVIII", Academia, 67, 1988, pp. 371-458.

García Melero, José Enrique, Literatura española sobre Artes plásticas, Madrid, Encuentro, 2002.

GutiÉRREZ HACES, Juana, "La preparación de un diccionario. Los apuntamientos... pertenecientes a la arquitectura del padre Pedro José Márquez", Anales del IIE, 16, 65, 1994, pp. 85-88.

Lillo Macina, Vincenza, El temazcalli mexicano. Su significado simbólico y su uso psicoterapéutico, México, Plaza y Valdés, 2007.

LóPEz Lujan, Leonardo et al., Xochicalco y Tula, Turín, Conaculta-Jaca Book, 2001.

LozoYA, Xavier, SPA: "Salute per aqua, el Temazcalli", Arqueología Mexicana, 74, 2005, pp. 54-57.

Malissard, Alain, Los romanos y el agua, Barcelona, Herder, 1996.

MÉndez Plancarte, Gabriel (comp.), Humanistas del siglo XVIII, México, UNAM (Biblioteca del Estudiante Universitario, 24), $1991^{4}$.

Mendoza CAStelán, Guillermo et al., Ipehualyo in Temazcalyo, fundamentos del Temazcalli, Texcoco, Universidad Autónoma ChapingoEditorial Futura, 2004.

Orozco Muñoz, Julio, Pedro José Márquez, su vida y su obra, 17411941, México, Historia y Poesía, 1941. 
Ortiz Buitrón, Agustín, "El temazcal arqueológico", Arqueología Mexicana, 74, 2005, pp. 52-53.

ORTIZ y SANZ, José, La arquitectura técnica en sus textos históricos. Los diez libros de architectura de M. Vitrubio Polión, Madrid, Akal (Fuentes de Arte, 2), 1987 (reprod. facs. de la ed. de Madrid, Imprenta Real, 1787).

Sosa, Francisco, Mexicanos distinguidos, México, Porrúa (Sepan cuantos..., 472), 1985.

VAldÉs García, Hilda J., "Pedro José Márquez, primer teórico de la estética mesoamericana", Ciencia y desarrollo, 151, 2000, pp. 60-65.

-, Obra de romanos. La formación del arquitecto, métodos de construcción y materiales según Vitruvio, tesis de Maestría, México, FFyL, UNAM, 2007.

WRIGHT, Jonathan, Los jesuitas, una historia de los "soldados de Dios", México, Dabate, 2005. 